\title{
The Concrete Testing by Ultrasonic Pulse Velocity (UPV)
}

\author{
Weerapol and Namboonruang ${ }^{1, a}$ \\ ${ }^{1}$ Department of Civil Technology and Architecture, Faculty of Science and Technology, Muban Chombueng Rajabhat University, \\ MCRU 70150, Thailand
}

\begin{abstract}
The study of an infrastructure development is continuously one of the targets of the national economic and social development plan. The purpose is to develop the local area sustainably and increase the ability of local authorities who have a direct role to promote and plan the other factors effectively. To success this plan the government agencies have to focus on the development dimension and taking into account other factors that may affect the way of life of the community.
\end{abstract}

Keywords: Rural infrastructure assessment, Half-cell potential, UPV test, Information engineering

\section{Introduction}

Recently, coastal and marine concrete structures were constructed from GGBS concrete because high volume of GGBS can contribute to reduction of temperature gradient [1,2]. Therefore, cement replacement materials such as fly ash, silica fume, blast-furnace slag, etc. may reduce greatly the probability of steel corrosion as well as the permeability of concrete $[3,4,5,6,7]$. In a study of the assessment of infrastructure development previous explained, the approach may not be sufficient to meet the in-depth local development in all dimensions. An integrating technology assessment research with public policy and It was proposed that the research process should include a means of engaging with the values of the political environment $[8,9]$. Therefore, the direction and knowledge determination need to be analyzed changes of circumstances which are suitable to the modern conditions occurred from the collaboration of multiple parties which requires the integration of various knowledge's for conducting the direction of local development as appropriate.

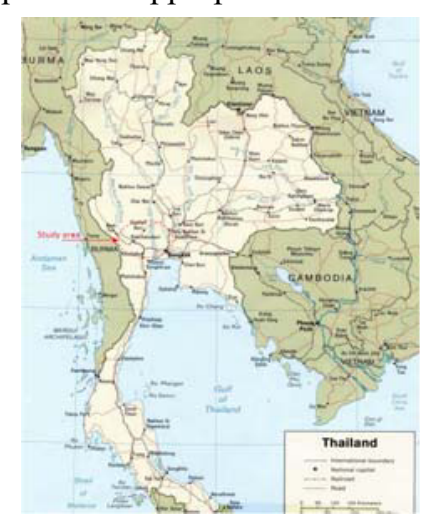

Fig 1. show the western rural organizations, Thailand (area of the study)

\section{Methodology}

Assessment of engineering infrastructure is starting role and one of the factors that is important to the development of local government agencies in Ratchaburi province in western region of Thailand in figure 1. The aim of this study is to focus on the integration of the physical dimension factor. This is to say the assessment of the local infrastructure conditions that area effected by various environmental conditions in each local area authority including society which need to assess the infrastructure needed by the people in the area. These two dimensions are integrated to understand the economic indicators, and policies for the planning application to compose a policy to meet the needs of the community and local development appropriately.

\section{Results and Discussions}

\subsection{Laboratories and in-situ tests}

As mentioned above, it was found that the concrete structure of local area authority's building is cracking. Disintegration of concrete and water permeability are the cause of corrosion of reinforcing steel, and some may not be able to use it in a secure environment. Considered by the strength components of 42 infrastructure examples in the western area of local organizations of Thailand, it was found that using nondestructive test by Rebound Hammer Test the strength value were approximately 84.19 percent compared to the coring test. According to this test it shows that the compressive strength of concrete appears likely to remain moderate and likely slightly lower than that of design.

\footnotetext{
${ }^{a}$ Corresponding author: bannork_civil@hotmail.com 


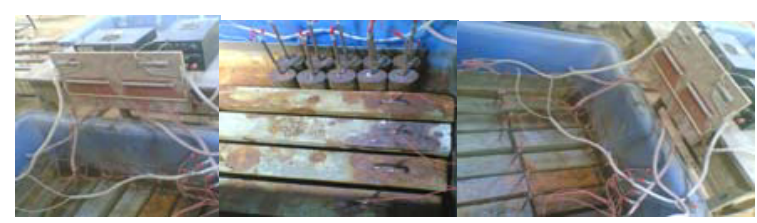

Fig 2. show the laboratory test of reinforced concrete specimens

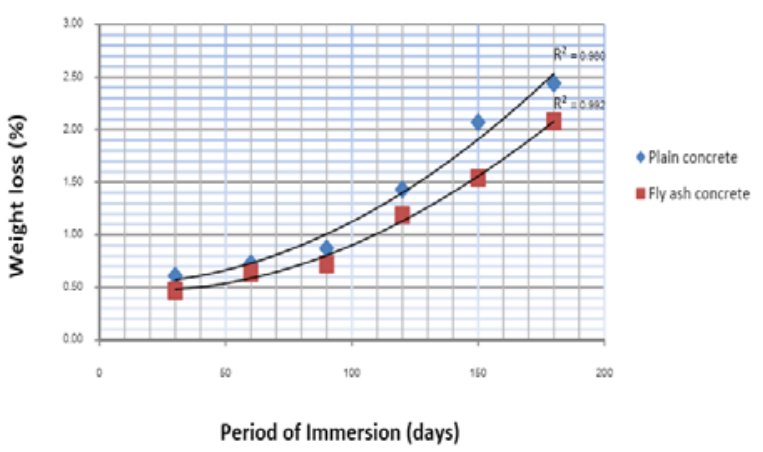

(a)

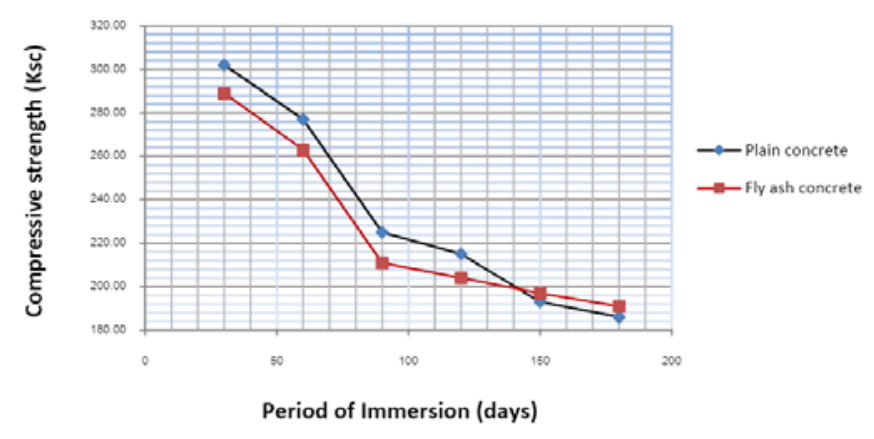

(b)

Fig 3. show relationship of weight loss (a) and compressive strength (b) of the reinforced concrete specimens

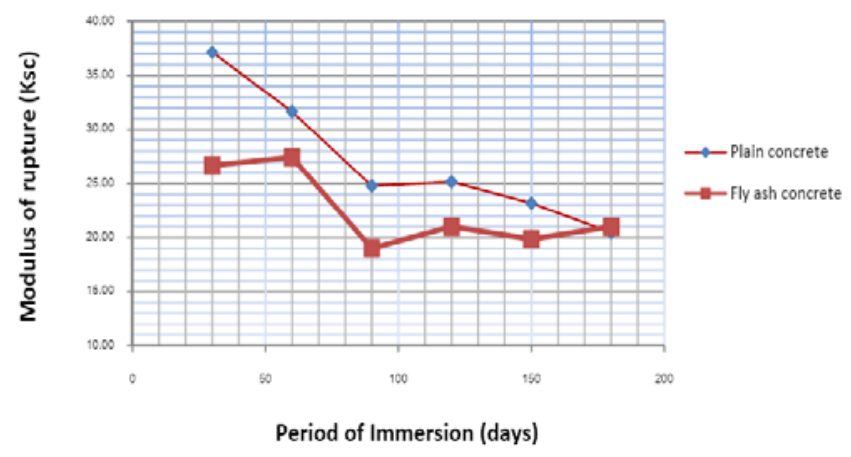

(c)

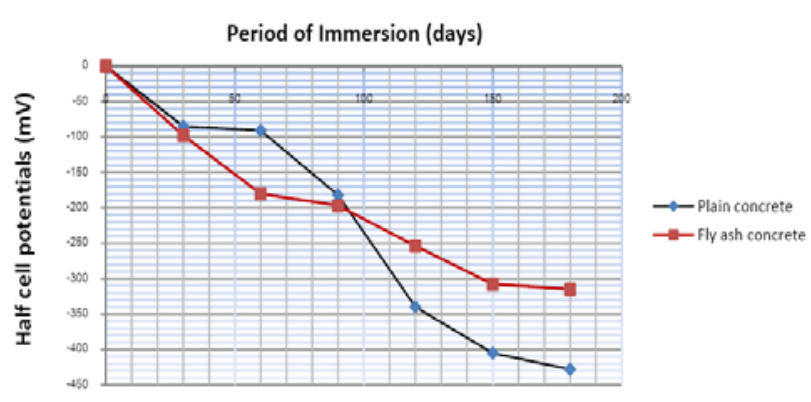

(d)

Fig 4. show relationship of weight loss (a), compressive strength (b), MOR (c) and half-cell potential (d) of the reinforced concrete specimens

Of the field tests considered by the weight loss of steel reinforcement in the concrete test of two example types compared to the test laboratory, results show that the electricity potential is approximately $350 \mathrm{mV}(410$ $\mathrm{mV}$ ) higher than that of the overall test. So it could be estimated that the weight of steel reinforcing concrete tends to corrosion more than one time as is consistent with the laboratory tests for the age of 90-180 days, the rate of reduction of steel weight are 1.980 and $1.603 \%$ of $-428 \mathrm{mV}$ and $-315 \mathrm{mV}$ respectively shown in figure $3-4$. This result confirms that the potential of the field tests can adequately explain the tendency to corrosion and the reduction of the weight of steel. As well as the concrete testing by Ultrasonic Pulse Velocity (UPV) test showed that the concrete condition is fair which tends to correspond with the voltage of electricity and the value of the strength with significantly, that is, the PV reduced by increasing of amount of the electrical potential difference and decreasing of the strength. The average value is of $3,180 \mathrm{~m} / \mathrm{s}$ for the average electrical potential difference at $-410 \mathrm{mV}$ of overall tests shown in figure 6.

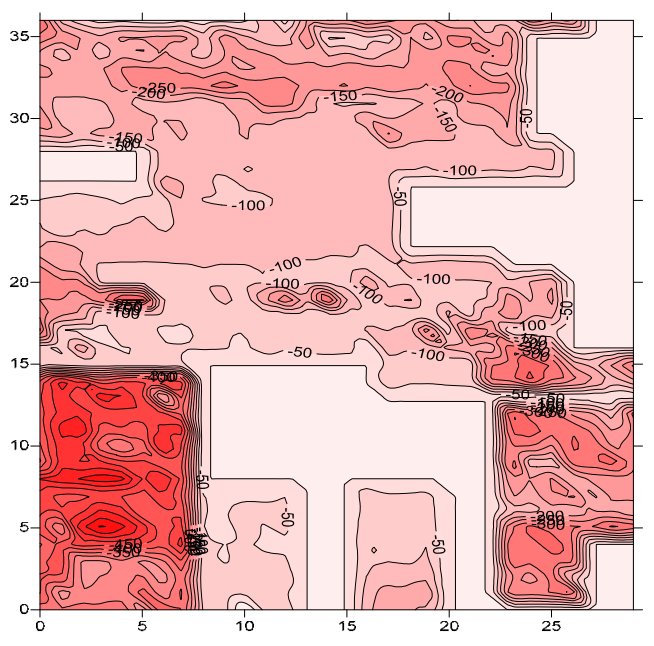




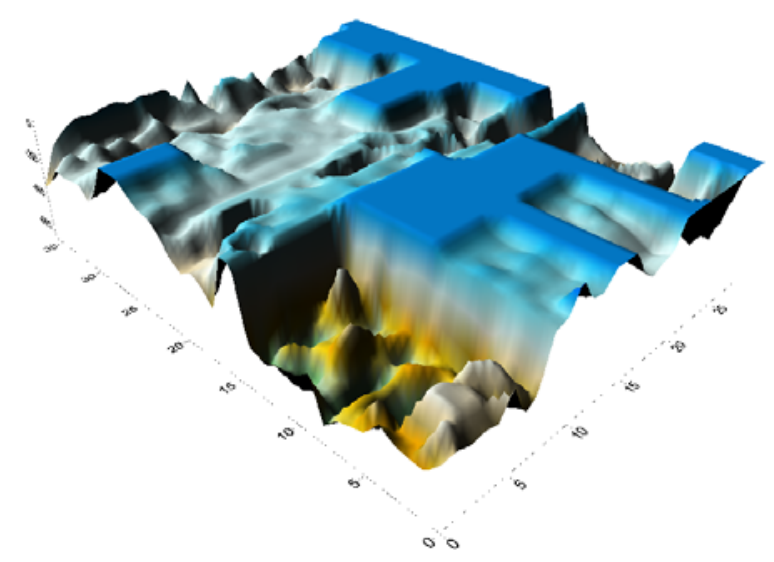

Fig 5. show potential profile of reinforced concrete slab by half-cell measurement

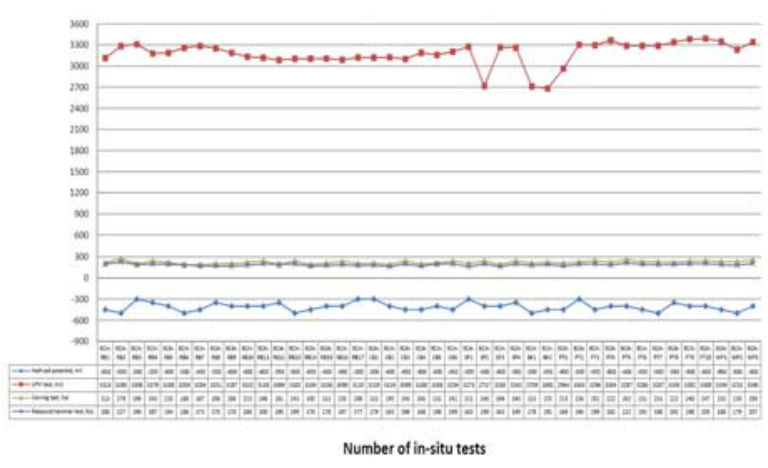

Fig 6. show relationship of half-cell potential, UPV, coring, and rebound hammer tests of infrastructure examples in the western area of local organizations of Thailand

\subsection{An economic}

For economic analysis and policy evaluation for assessment of infrastructure found that they should be repaired and maintained which will prolong the service life being more than 10 years compared to overall infrastructure. Of the above factors, when analyzed in terms of economics, the government benefits from the use of the building longer than that of design and operation (Service life $_{50}$ ) at percentage of 20.00 and 28.57 (Service life ${ }_{35}$ ). If consider on an economic value of the maintenance of overall local infrastructures, government will get benefit about 94.57 million baths.

\subsection{An evaluation of the information engineering database management system}

For the participation of the community in view of the local infrastructure, it was found that the participants had the most satisfied for four factors; such as an overview of service infrastructure components $(\bar{x}=4.33)$, benefits of the infrastructure policy $(\bar{x}=4.53)$, the appropriateness of the infrastructure $(\bar{x}=4.26)$, and the knowledge that was available to meet the local development $(\bar{X}=4.70)$ as well as an evaluation of Information Engineering system of local infrastructure. Therefore, the documents and information systems show an overall at a good level $(\overline{\mathrm{X}}=3.64)$. The solved - Improved document system is at a high level $(\bar{x}=3.61)$, and satisfaction in the operating system $(\bar{X}=3.69)$. Finally, the satisfaction of website is at the moderate level $(\overline{\mathrm{X}}=3.43)$ shows in (e), (f), (g) and (h) of figure 7.

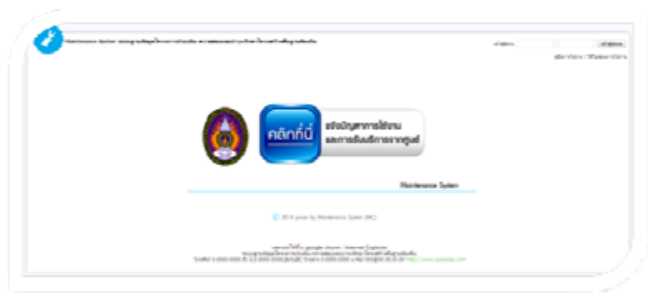

(e)

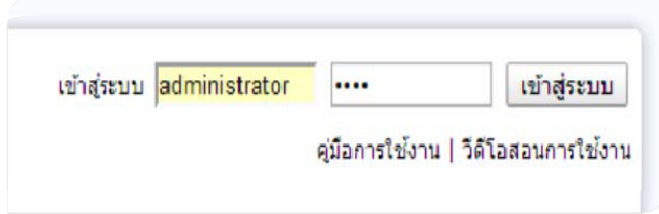

(f)

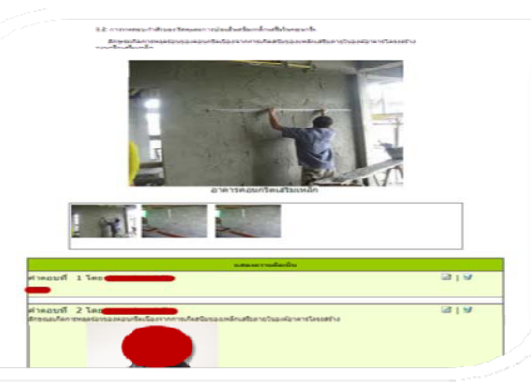

(g)

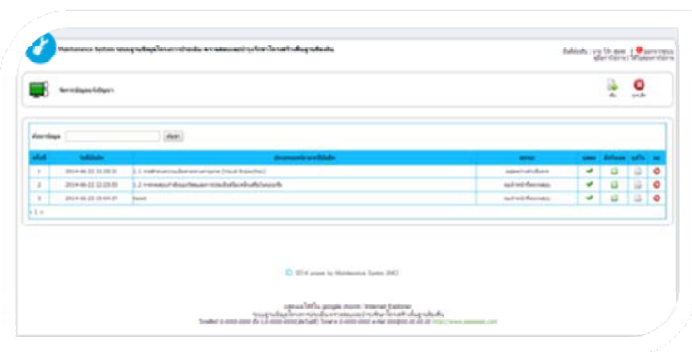

(h)

Fig 7. show the website pattern of the information engineering database management system

\section{Conclusions}

In $\mathrm{RC}$ floor slab of the rural infrastructure public building where its thickness is thin compared to its effective span length, the crack pattern generates due to 
the corrosion caused by the repetition of moisture and chloride condition. Generally, in the early stage of deterioration, cracks generate in perpendicular direction to the axis of the structure where the distribution of steel bars are less and weight of steel reinforcing concrete tends to corrosion more than one time as is consistent with the laboratory tests for the age of 90-180 days

The concrete testing by Ultrasonic Pulse Velocity (UPV) test showed that the concrete condition is fair which tends to correspond with the voltage of electricity and the compressive strength of concrete appears likely to remain moderate and likely slightly lower than that of design on in-situ tests.

The government benefits from the use of the infrastructure longer than that of design and operation of $20 \%$ at Service life 50 . For the evaluation of the use of information technology infrastructure by local overview of the four factors found that user satisfied in the use of information technology systems engineering for managing local engineering infrastructure at high level.

\section{Acknowledgements}

The author would like to express gratitude to researchers, namely Dr. Rattanakorn Rawangkul, STRR Engineering CO.,LTD, Thailand, Assoc. Prof. Dr. Wanchai Yodsudjai, Head of Department of Civil Engineering, Kasetsart University, Assoc. Prof. Dr.Trakool Aramraks, Department of Civil Engineering, Kasetsart University, Thailand for their invaluable help and constant encouragement throughout this research. Sincere thanks to the Department of Civil and Architecture for instrument test supporting and Muban Chombueng Rajabhat University, MCRU for partial financial support.

\section{References}

1. D.M. Roy, A. Kumar and J. Rhodes, ACI SP-91, V.M. Malhotra, ed., Vol. 1423, 1986.

2. Z.G. Matta, Concrete Intemat., 14(5) (1992) 4748.

3. A.A. Ramezanianpour, Effect of curing on the compressive strength, resistance to chloride-ion penetration and porosity of concretes incorporation slag, fly ash or silica fume, Cem. Concr. Compos. 17(1995) 125- 133.

4. G.J. Osborne, Durability of portland blast-furnace slag cement concrete, Cem. Concr. Compos. 21 (1999) $11-21$.

5. E.F. Irassar, M. Gonzalez, V. Rahhal, Sulphate resistance of type Vcements with limestone filler and natural pozzolana, Cem. Concr.Compos. 22 (2000) 361-368.

6. K.M.A. Hossain, M. Lachemi, Corrosion resistance and chloride diffusivity of volcanic ash blended cement mortar, Cem. Concr. Res. 34 (4) (2004) 695-702.

7. O.E. GjArv, Effect of condensed silica fume on steel corrosion in concrete, ACI Mater. J. 92-M60 (1995) 591- 598.

8. OCce of Technology Assessment. Development of Medical Technology: opportunities for Assessment, U.S.Government Printing OCce, Washington, DC, 1976.

9. B. Bozeman, F. Rossini, Technology assessment and political decision-making, N.Z. Med. J. 104 (1991) 199-202.

10. ASTM C 42. Standard Method for Obtaining and Testing Drilled Cores and Sawed Beams of Concrete, West Conshohocken, USA, (2008).

11. ASTM C 597 Standard Test Method for Ultrasonic Pulse Velocity Through Concrete, West Conshohocken, USA, (2008).

12. ASTM C 805 Standard Test Method for Rebound Number of Hardened Concrete, West Conshohocken, USA, (2008).

13. ASTM C876 Standard Test Method for Half-Cell Potential of Uncoated Reinforcing Steel in Concrete, West Conshohocken, USA, (2008). 